By: Diane L. Gill

Gill, D.L. (1997). Measurement, statistics and research design issues in sport and exercise psychology. Measurement in Physical Education and Exercise Science, 1, 39-53.

Made available courtesy of Taylor and Francis:

http://www.informaworld.com/openurl?genre=journal\&issn=1091-367X

***Note: Figures may be missing from this format of the document

To identify measurement, statistics, and design issues is a format way of asking, "How do we answer our research questions?" Before addressing that question, however, we must first ask, "What are our research questions?" As a specialist in sport and exercise psychology, I interpret my main task as identifying the research questions and content issues of sport and exercise psychology. If content specialists can accomplish that task, then the measurement specialists can work with the content experts to answer those questions.

The theme that continues throughout this article is the one take-home, bottom- line message for both sport and exercise psychology scholars and our measurement colleagues: Identifying our research questions, or achieving conceptual clarity, is the source and solution for our measurement, statistics, and design issues. When research has a clear purpose and conceptual framework, when constructs are clearly defined, and when clear and relevant questions are asked, we solve many problems. Moreover, we get better advice when we ask the experts.

My favorite research advice comes from Lewis Carroll's (1865/1992) Alice's Adventures in Wonderland. Alice (the searching researcher) asks Cheshire-Puss (the resident measurement expert) for advice, "Would you tell me, please. which way I ought to walk from here?" Cheshire-Puss returns the question (as do all expert advisors): "That depends a good deal on where you want to get to." When Alice replies that she doesn't much care where, the sage responds, "Then, it doesn't matter which way you walk." If we cannot tell our advisors where we want to get to, we cannot expect them to tell us how to get there.

\title{
THE CONTENT OF SPORT AND EXERCISE PSYCHOLOGY
}

Before setting a specific destination of "where we $w$ ant to `et to. let s set a genes a: destination for the content of psychology Psychology asks many of the lain- questions asked by other content areas of exercise and sport science and share- many of the same issues. Perhaps the most unique. salient feature of psychology content is the focus on the unobservable - thoughts. feelings. and all the "toughs feel' things that we cannot really touch and feel Latent constructs are not merely measurement tools or terms for structural modeling they are the essence psychology content

More formally, most psychology texts define psychology as the scientific stud of behavior. Thus, we can simply add our context and define sport and exercise psychology as the scientific study of behavior in sport and exercise context Although that definition does not seem so latent. as we narrow our path and delve further into the content, we find the $\mathrm{ABCs}$ of psychology content $\mathrm{A}=$ affect. $\mathrm{B}$-behavior. and $\mathrm{C}=$ cognition Within psychology, these ABCs - feelings. action-, , and thoughts - are all behavior. and behavior is the ultimate outcome for psychology Psychologists try ${ }^{-}$to understand and explain behavior. as a whole, by looking at the affective. behavioral. and cognitive components and correlates

\section{A Model for Sport and Exercise Psychology}

Sport and exercise psychology researchers focus on holistic behavior rather than on isolated parts of behavior Within exercise and sport science, psychological research that focuses more on components and processes (e.g.. learning and cognitive processing) is done in the area of motor behavior Sport and exercise psychology 
specialists typically take a more holistic. social-psychology approach We try to understand behavior in sport and exercise settings as influenced by individual characteristics (personality. affect. cognitions) and environment (especially social environment—e.g.. coaches, group, social culture). The guiding model for sport and exercise psychology is reflected in Kurt Lewin's (1935) classic formula. $B=f(P, E)$, where behavior $(B)$ is a function of person $(\mathrm{P})$ and environment $(E)$

\section{Measurement, Statistics, and Design in the Psychology Model}

Our measurement. statistics. and design issues reflect that dominant model. Measurement issues emphasize personality $(P)$ measures. That emphasis started with the earliest sport psychology research using the personality measures of general psychology, continued with the development of more specific personality or individual-difference measures, and today emphasizes individual dispositions and perceptions related to socialcognitive models (e.g., motivational orientation, perceptions, expectations. attentional style). We do not spend much time on behavior $(B)$ measures, despite their central role in psychology. Sport psychology research typically has defined behavior as performance or participation and has increasingly included fitness or healthrelated outcomes. However, sport and exercise psychologists have left the measurement issues to others. Similarly, sport and exercise psychologists do not spend time on environmental $(E)$ measures. Environmental conditions and variables exist and might be classified, but measurement issues are ignored.

Typical sport and exercise psychology research designs reflect the Lewin model. Sport psychologists might look at the relation of a $P$ variable (e.g.. trait anxiety) to a $B$ variable (e.g., performance) or, even more likely, might use factorial models considering the interaction of $P$ and $E$ variables in predicting behavior. For example, a typical research design might examine high- versus low-anxiety persons in competitive versus noncompetitive situations with performance as the dependent variable. Given the typical factorial designs, the logical statistics are analysis of variance, and. often, multivanate analysis of variance (MANOVA). More recently. sport and exercise psychologists have used more continuous $P$ measures with regression analyses as well as MANOVA. but the basic design and statistical models are the same.

Before offering suggestions for advancing beyond this basic model, I review the progress sport psychology has made with measurement, statistics, and design within this framework; highlight some current issues; and discuss directions and options.

\section{PROGRESS IN SPORT AND EXERCISE PSYCHOLOGY MEASUREMENT}

From its emergence as an identifiable research specialization in the 1960s, sport and exercise psychology has improved upon measurement, design. and statistical procedures. Some of the advances also apply to other content areas within exercise and sport science, but I focus in this article on progress in measures and research related to individual differences (which, in a measurement sense, is the most notable progress in sport and exercise psychology).

Personality is the first characteristic most people think of when they think of psychology. In fact, personality is one of the earliest topics for sport psychology research. In a recent chapter on measurement in sport psychology, Heil and Henschen (1996) noted the early work with personality measures. They reported that Coleman Griffith (the so-called father of sport psychology) used personality measures and interviewed athletes in the 1930s and 1940s. They did not mention, but other sources (e.g.. Gould \& Pick, 1990 have indicated. that Griffith also many laboratory tests and measures (e $\mathrm{g}$, reaction time. motor coordination attention) to assess athletes and took a more scientific and broader view of sport behavior than was implied in Heil and Henschen's chapter But. as Heil and Henschen noted. personality measures dominated early work and hit a peak and valley, dependmg on the viewpoint) around 1969 with the popular but psychomet rically unsound Athletic Motivation Inventory Tutko. Lyon. \& Ogilvie. 196 Since 1969. sport psychology has gradually moved away from global personality measures to more specific measures 
One of the most important advances for sport psychology measurement was the evolution from general personality measures to sport-specific measures of individual differences relevant to sport and exercise behavior Martens's (1975) development of the Sport Competition Anxiety Test (SCAT) initiated the move to sportspecific measures. Martens drew upon related theoretical and empirical work on anxiety to develop a model of competitive anxiety. reasoning that a sport competition - specific measure would better identify individuals who become anxious in competition than would more general anxiety measures. The SCAT was developed following appropriate psychometric standards of test development and validation

Other sport and exercise psychologists followed Martens's (1975) example to develop other sport-specific instruments to measure relevant individual differences Canon. Widmeyer. and Brawley (1985) developed the Group Environment Questionnaire (GEQ) to measure cohesion Gill and Deeter (1988) developed a sportspecific measure of competitive achievement orientation. Sport Orientation Questionnaire (SOQ). and subsequent sport anxiety measures have improved on the SCAT

\section{Multidimensional Measures}

Many of the most important constructs of sport and exercise psychology are multidimensional, and recently we have used multidimensional conceptual frameworks and measurement procedures to develop appropriate multidimensional measures. For example. anxiety is now conceptualized and examined as a multidimensional construct. usually with cognitive anxiety/worry and somatic anxi - ety/physiological arousal dimensions. Smith, Smoll. and Schutz (1990) developed the Sport Anxiety Scale (SAS) with cognitive. somatic, and distraction dimensions Like the SCAT, the SAS assesses individual differences in the tendency to become anxious in sport, but the SAS likely will replace the unidimensional SCAT in research and applications based on multidimensional approaches to sport anxiety.

\section{States and Traits}

The issue of state and trait measures is related. Personality typically implies trait measures - that is, measures of enduring dispositions that reflect a tendency to behave in a given way (e.g., anxious) consistently. Personality states are more immediate; a person might be in a state of high anxiety at a particular time but might not necessarily have high trait anxiety. Personality theories assume that traits are related to states. For example, the high-trait-anxious person tends to have high state anxiety more often than a low-trait-anxious person. However, states are also affected by situation. Anxiety research, in particular, differentiates states and traits, and our measures reflect that differentiation. For example, Martens, Vealey, and Burton (1990) developed the multidimensional Competitive State Anxiety Inventory-2 (CSAI-2), now widely used in sport psychology research and practice.

\section{Perceptions and Cognitions}

In moving away from global personality, sport psychology also moved away from personality dispositions (although not entirely) to emphasize more immediate perceptions and cognitions. This work reflects the strong social-cognitive movement in psychology through the 1980s, and sport and exercise psychology has adopted that approach with related models and measures. Within that general social-cognitive approach, sport and exercise psychologists have investigated and measured attributions, expectations, self-perceptions, and, particularly, self-efficacy. Because these constructs relate to an immediate situation, they are measured for that immediate situation, and we do not have standard measures with established reliability and validity. introducing some measurement issues.

For example, self-efficacy is particularly popular and useful in research and practice. Self-efficacy is the belief that one has the capability of successfully performing a task or behavior. Bandura $(1977,1986)$ offered guidelines for measures. Most measures are similar, asking respondents to rate how confident they are that they ean perform a specific task (e.g., finish a $10 \mathrm{~K}$ run in $35 \mathrm{~mm}$ ) on a scale ranging from $0 \%$ (not at all confident) to $100 \%$ (absolutely certain). However, the specific referent tasks are not standard, and researchers seldom pilot measures or check reliability or validity in any way. 
Bandura's $(1977,1986)$ model suggests three dimensions of efficacy-strength (represented by the percent scale), level (a hierarchy of tasks), and generality (the extent that efficacy generalizes to related tasks). Yet, we seldom assess those dimensions or consider the theoretical underpinnings when developing measures. More often, simple scales and items are developed for a particular study, used with little if any pilot testing, and interpreted as though they were valid measures of particular social-cognitive constructs.

\section{Measures of Affect and Emotion}

Sport and exercise psychologists have been studying. and measuring anxiety emotion. for some time. More recently. psychology has seen a reemergence of in, broader area of emotion and affect. Conceptual models of emotion call for differnet approaches than the self-report measurement approaches used in sport and exercise psychology Emotion clearly is conceptualized as multidimensional. and the dimensions extend to physiological and evaluative dimension. as well as cognitive judgments.

\section{CURRENT MEASUREMENT ISSUES IN SPORT AND EXERCISE PSYCHOLOGY}

Although we have made progress, sport and exercise psychologists continue the debate issues related to individual-difference measures.

\section{Proliferation}

There are too many sport psychology measures. In the first edition of Directory Psychological Tests in the Sport and Exerctse Sciences, Ostrow (1990) listed almost 200 different measures. The updated edition now in preparation might well double that number. Very few of those measures meet even mimmal psychometric standards of test development. most were simply developed and used for a particular study without preliminary item analyses and reliability and validity testing.

\section{Statistical Shortcomings}

As Schutz and Gessaroli (1993) noted, even when some psychometric information is provided. statistical methods are weak. often involving misapplication. misunderstanding. or misinterpretation of some aspect of factor analysts Developers of sport psychology measures seldom use multitrait - mulitmethod matrices, typically ignore (if even acknowledge) conceptual models by using exploratory methods rather than confirmatory analyses. and often combine subscores (developed from analyses yielding uncorrelated factors) into global scores without ever checking for second-order factors or hierarchical structures.

\section{Lack of Conceptual Clarity}

To these statistical shortcomings identified by Schutt and Gessaroli (1993)T would add that sport psychologists usually stop psychometric analyses with alpha coefficients of internal consistency and never consider the more important validity issues. If measures are to be useful to sport and exercise psychology, they must validly measure some construct that is relevant to sport and exercise behavior. Of course, we cannot assess validity if we do not know what we are trying to measure, and we return to the bottom-line message: Conceptual clarity is the first step. If we know what we want to measure, we can consider validity of purported measures. Otherwise. inventories might include interrelated items yielding a score, but we have no justification for interpreting the score.

Even with the measures that were developed following appropnate psychometric standards, sport psychology has unresolved issues. Gauvin and Russell (1993) hIghlighted two key issues concerning our psychological measures - specificIty and cross-cultural applications.

\section{Specificity}

The SCAT initiated the evolution to more sport-specific tests, sport psychology continued to move in that direction, and now we are at the point of deciding whether we have gone too far in that direction. For example. sport psychologists have developed measures of psychological skills (e.g., attentional style. sport confidence) specific to sport, but some sport psychologists advocate even more specificity. Measures of attentional style 
have been developed specific to tennis and to baseball/softball. The growing number of sport psychology consultants interested in assessing psychological skills of athletes for applied psychological skill training has added to this problem. A consulting or clinical perspective calls for very context-specific assessment for very specific purposes, and that might be at odds with the desire for more reliable and valid measures of psychological constructs. Sport-specific measures have advanced sport and exercise psychology research and practice, but further specificity detracts from generalizability and results in a case or clinical report that is not applicable or interpretable beyond the immediate situation.

\section{Cross-Cultural Applications}

Gauvin and Russell's (1993) second point relates to the cross-cultural use of psychological measures. This is a critical issue, as sport and exercise psychology is finally engaging in long-overdue cross-cultural and international research. Several measures have been translated and used around the world. For example, several $\mathrm{PhD}$ students working with me and with other advisors have used some of our anxiety and motivational measures in other countries. Translation of items and measures requires care. Some guidelines for translation, back-translatIon, and other procedures exist. but. beyond that. as Gauvin and Russell noted. we must also consider the cultural influences on the measures Words, phrases. test items. ai underlying constructs are related to their cultural context, when measures del.: oped within one culture are taken to another. we might not be measuring the same thing.

Gauvin and Russell (1993) specifically discussed cross-cultural measures. but we can extend that issue to diversity in general As sport and exercise psychology extends to more diverse physical activity contexts. we are dealing with more diverse participants. and our current measures typically developed for competitive s poi $t$ participants in school settings might not be appropriate.

\section{Developmental Issues}

Developmental issues are a major concern as we examine different age groups. Measures for children are problematic and must consider developmental level. which involves not only language. cognitive. and attentional development but also the developmental meaning and understanding of constructs we are trying to assess. Developmental issues must also be considered with older adults Like many colleagues, I am working with older adults in my recent research, and that brings up a variety of measurement issues. As well as attending to details such as large print and a limited number of items. the constructs and meanings are critical. Task and ego achievement orientation, which were prominent in my earlier research and remain prominent in current sport psychology research. are not large issues or even little issues for the older adults in my current research Constructs that are of more concern (e.g.. psychological well-being, efficacy for physical activity) take on different meanings for older adults and. moreover. vary greatly within the range of older adults.

\section{Issues With Motlvational Orientatlon Measures}

In addition to the issues raised by Schutz and Gessaroli (1993) and Gauvin and Russell (1993). the motivational measures that dominate current sport and exercise psychology literature illustrate more specific measurement issues. Marsh (1994) examined some of sport psychology's more psychometrically sound measures of sport motivation orientation, including Roberts's (1993) Perceptions of Success Questionnaire (POS) and Gill and Deeter's (1988) SOQ. These measures are based on current social-cognitive achievement models emphasizing two general contrasting dispositional goal orientations variously termed (a) mastery, task. and intrinsic orientation and (b) ego. competitive. and extrinsic orientation. With his considerable psychometric skills and experience with such measures. Marsh compared the POS and the SOQ and, based on varying correlations and confirmatory analyses, concluded that SOQ competitiveness reflects a task orientation, whereas POS competitiveness reflects an ego onentation.

Based on these findings and other observations of related measures, Marsh (1994) cautioned sport psychologists to beware of jingle fallacies (scales with the same label reflect the same construct) and jangle fallacies (scales with different labels measure different constructs) and to pursue construct-validity studies more vigorously to test the interpretations of measures. Marsh advocated validity studies, but we can also return to the bottom-line 
message: Conceptual clarity is the first step in specifying and delineating our constructs for later validation and interpretation.

Marsh's (1994) article suggests other issues. These goal-orientation measures are some of our most sound and widely used measures, but do we need them? Do they all measure unique, important constructs? Do the scales on the Task and Ego Orientation in Sport Questionnaire (TEOSQ; Duda, 1992), the POS, the SOQ, and other measures really reflect different underlying constructs, or are they all variations on a theme? Sport and exercise psychology specialists should ask these questions, as our students and colleagues continue to use these measures in research. Sport psychologists seem to be quick to use the measures but pay little attention to clarifying the questions and issues that prompted the development of such measures in the first place.

The availablity of these measures prompts sport psychologists to focus on the $P$ part of the Lewin model to the neglect of other components, processes, and a holistic approach. For example, the TEOSQ has prompted us to rely on individual differences and dispositions in our research on goal-oriented behavior, but most theones and observations suggest that the immediate situation and larger social context have more influence on goal-directed behavior.

Even if dispositional measures such as the TEOSQ are appropriate, scoring and analysis are problematic. The TEOSQ. like many of the more widely used measures, is multidimensional, with task and ego subscales. Theoretical models suggest that high - task-oriented people behave in certain ways (e.g., persist in the face of challenges), whereas ego-oriented people behave differently (e.g., focus on outcomes, make compansons to others). How are TEOSQ scores used to examine predictions? Some researchers use median splits to identify high-task and high-ego individuals, some look at difference scores, some use a 2 x 2 model, and still others use regression models with the range of scores. None matches the theory and measures very well. Personally, I don't like any of the solutions, but I use regression analyses because scores are distributed and clustered rather than extreme. However, scores are highly skewed (task scores are particularly high), regressions do not deal well with interactions or some of the theoretical predictions, and, again, sport psychologists have been distracted by the scoring and classification debates and have not attended to issues related to sport and exercise behavior.

\section{Exercise/Physical Activity and Psychological Measures}

Most of our better measures were developed for competitive sport contexts and not tap constructs of more concern in the growing research related to exercise art. health-related physical activity Some motivational measures have been adapted for exercise settings. but the expanded research in this area requires more diver s, measures. In particular. health-related quality of the QOL. see Rejeski. Bra. le d Shumaker. 1996. for a review i is a construct with which many sport and exert, s: psychologists are struggling National Institutes of Health funding guideline for the inclusion of QOL measures along with typical health and medical outcome measures. and QOL or psychological well-being practical concern for content area However. close inspection of the current QOL literature revealed hodgepodge of varying combinations of selected depression. anxiety, and mood measures. So tar. health psychologists and behavioral medicine researchers have provided little guidance in delineating. coherent constructs and developing sound measures of health-related QOL Sport and exercise psychologists. along with measurement colleagues. could contribute i. this effort and further advance research and practice related to health-related physical acting.

\section{STATISTICS AND DESIGN ISSUES}

In this article. I purposely focus on the psychological measurement issues, because they are the most unique to the sport and exercise psychology area. and because they are indeed major issues. Sport and exercise psychology also has issues related to statistics and design I do not address these issues in depth here. Other sources have covered statistical and design issues more effectively. and many of the issues are shared with other content areas and are covered in other articles in this issue of Measurement in Physical Education and Exercise Science. In this article. I highlight issues that are particularly relevant for sport and exercise psychology. noting progress and continuing issues 
At the 1993 conference of the International Society of Sport Psychology (ISSP) Schutz (1993) provided the following list of statistical and measurement issues in sport psychology:

- Hypothesis testing s heuristic research

- When the null hypothesis is the research hypothesis

- $\quad$ The measurement and analysis of change

- Measuring the magnitude of an effect

- Statistical sophistication c multivariate obfuscation

- $\quad$ The measurement of latent constructs

- The proliferation of scales and inventories

- $\quad$ Establishing the validity. reliability and stability of factor structures (p 119:

The last three issues relate to sport psychology measures and were covered in earlier sections. The first issue is significant for sport and exercise psychology but in a larger sense than was discussed by Schutz.

\section{Qualitative Research Standards}

For sport and exercise psychology, the issue is not really hypothesis testing versus heuristic research. Theoretical research can and should have heunstic value; as stated in Lewin's (1951) classic line, "there is nothing so practical as a good theory" (p. 169). The larger issue for sport and exercise psychology is dealing with the growing interest in "qualitative" research. Martens (1987) called for more heuristic research and adoption of alternative methods, such as case studies and introspective reports. Since then, several sport and exercise psychologists have incorporated alternative, qualitative methods, and some have provided models for that work. Scanlan, Stein, and Ravizza's (1989) work on sport enjoyment and stress, based on in-depth interviews with elite figure skaters, provided such a model.

Unfortunately, others have taken Martens's (1987) call for alternative approaches as justification for abandoning all scientific rigor, measurement standards. hypotheses testing, and statistical analyses. The best qualitative research, from my perspective, is done by scholars with experience in traditional methods who see new possibilities but not a cure-all, and who recognize limits of qualitative approaches and what they trade off by leaving traditional approaches. Good qualitative research - and it should be noted that qualitative research encompasses many diverse methods and approaches (see Denzin \& Lincoln's excellent 1994 Handbook on Qualitative Research)_demands careful planning and rigor. The challenge for sport and exercise psychology, as well as for pedagogy and other content areas that incorporate qualitative approaches. is to develop standards and guidelines for conducting and evaluating that research. Content specialists are struggling with these issues, and any help from measurement specialists would be appreciated.

\section{Statistical Issues}

The null hypothesis as a research hypothesis is nonsensical, and I have no other insights to add beyond Schutz's (1993). However, I add that sport psychology research seldom presents clear, testable hypotheses, even when introductions appear to hypothesize something. Many sport and exercise psychology papers present results that "support" a model or theory, but careful reading of the introduction and consideration of the method reveal no way that any alternative results would have disproved the theory or led to any other conclusions. Clearly, sport and exercise psychology research is no model or Platt's i 1964i ${ }^{--}$strong inference approach. which Landers (1983) advocated for our area Again, the point come back to the bottom-line Conceptual clarity is the first step.

Measurement of change is less central to our research now than it was 15 years ago wlien sport psychologists conducted more lab research with repeated trials motor tasks Related issues are more central for motor behavior. and is discussed in the Christina article in this issue.

Researchers are more inclined to measure the magnitude of effects and to report effect sizes and $R^{2}$ values in exercise and sport science publications As Schutz (1993) pointed out. we still have far to go. and. moreover. sport psychologists can do much better evaluating the effects This relates to a point Rejeski (1996) made in an 
American College of Sports Medicine (ACSM) lecture concerning QUI measures. Recently. Rejeski has been exploring physical activity and QOL with colleagues from medicine and health In the ACSM lecture. he stated that ecological validity and climcal significance might well be more important than our typic<<: psychometric tests regarding such issues Researchers must develop measures constructs and behaviors that are tmportant to the health and well-being of our participants.

The issue of statistical sophistication versus multivanate obfuscation is my personal favorite Many sport and exercise psychology papers offer multivariate obfuscation. often in misguided attempts to follow the advice of measurement and statistics specialists by using the most complex techniques and computer programs Give u' a hammer, and everything looks like a nail. More specifically. for sport and exercise psychology. it is an SPSS or LISREL program that hammers all data About 10 year= ago. MANOVA programs became commonplace. and many sport and exercise psychology reviewers and advisors told everyone to use MANU A whenever possible Today. I see similar enforcement of structural equation modeling ( SEM) as the gateway to acceptability Rather than view a multivariate method as the automatic solution researchers should first ask if they have a multivariate question If not. a multivariate method is not needed and probably not desirable Correcting for expenmentwise error rates with Bonferroni or other techniques might be a better alternative if the questions of interest involve separate univanate comparisons Moreover, with multivariate results, scholars must be prepared for a complex and unclear multivanate interpretation Statistical follow-up procedures are not universal. and the multivariate solutions do no fit our conceptual models very well.

SEM offers promise for sport and exercise psychology, and confirmatory factor analysis (CFA) certainly is appropriate to test or confirm a model. However. SEM is no substitute for careful and appropriate conceptualization and design Many sport and exercise psychologists overinterpret SEM to infer causality and conceptual relations and forget that it is a statistical technique Although CFA is appropriate to test a model, exploratory techniques might be more appropriate to delineate constructs and refine models For example. multidimensional scaling (MDS techniques are seldom used in sport and exercise psychology, but MDS might be a particularly promising approach for delineating and refining our eonstructs, models, and measures. Most of all, SEM, as well as any other statistical technique that dominates our research literature, tends to limit research. We plan and design studies that fit the techniques and measures rather than look first at our questions.

Measurement specialists who are asked for statistical advice would do well to refuse to give any directions until content specialists specify a clear destination and question. Conceptual clarity is the first step to efficient research efforts and more useful research outcomes.

\section{SUMMARY AND DIRECTIONS}

We have made progress in sport and exercise psychology measurement and methodology, but few issues are resolved. Most of our progress and unresolved issues involve measures of our psychological constructs. Sport psychologists have developed sport- specific multidimensional measures and used them in conceptually based multivariate designs. Several unresolved issues relate to the psychometric properties of our measures and the appropriateness of our designs and analyses. However, the key issue, underlying all others, is the need for conceptual clarity. Sport and exercise psychologists must focus on the sport and exercise behaviors of interest, use appropriate conceptual models, and ask clear, relevant questions. Then we can work with measurement colleagues to find measures and methods that match those questions.

Further complicating the issues is the fact that sport and exercise psychology questions are changing. Not only must we clarify the current questions and models. but we must also prepare for new approaches. Specifically, the Lewin model, which still dominates sport and exercise psychology, is no longer sufficient. The Lewin model is linear and unidirectional, whereas current thought emphasizes dynamic processes and reciprocal relations and approaches the complexity notions that are taking over in other scientific areas. We must put the Lewin model into motion despite the realization that so doing will complicate the measurement and methodology issues beyond what can reasonably be addressed today. 
For example, Bandura's (1977) original self-efficacy theory was a linear model with self-efficacy as the key mediating variable between interventions and behavior change. In his more recent social-cognitive framework, Bandura (1986) proposed a triadic, reciprocal relation among person $(P)$, environment $(E)$, and behavior $(B)$, with the three constantly interacting with one another and changing over time. Similarly, Markus and Wurf (1987) proposed a dynamic self-concept that involves multiple interacting components constantly changing over time; Lazarus (1993) moved from his earlier conceptions of stress to a model of emotions that involves reciprocal, dynamic multidimensional relations.

Our current methods cannot deal adequately with these models. The best we can do is take snapshots when we need videotapes of the action. Measurement specialists cannot tell us how to measure. anal $\}$ :- and interpret dynamic reciptor relations and processes today But, it sport and exercise psychologtsts set a clear destination. perhaps the measurement community can suggest steps in the ugh direction.

\section{REFERENCES}

Bandura. A (19 $7^{7}$, Self-efficacy Toward a unifying theory of behavioral change Psychological Renew 84.191215

Bandura. A t 1986t Social foundations of thought and action: A social cognitive thence Engleswood Cliffs. NJ Prentice Hall

Carroll. L (1992) Alice's adventures in wonderland and Through the looking glass New York Dell (Alice's adventures in wonderland originally published in 1865)

Carron. A V , Widmeyer. W N . \& Brawley. L R (1985) The development of an instrument to assess cohesion in sport teams The Group Environment Questionnaire Journal of Sport Psychology - 244-266

Denzin. N K . \& Lincoln. Y S (1994) Handbook of qualitative research Thousand Oaks. CA Sage Duda, J L (1992) Motivation in sport settings A goal perspective approach In G C Roberts (Ed Motivation in sport and exercise (pp $\left.5^{7}-9 \mathrm{I}\right)$ Champaign. IL Human Kinetics

Gauvin. L . \& Russell, S J t 1993ï Sport-specific and culturally adapted measures in sport and exercice psychology research Issues and strategies In R N Singer. M Murphey. \& L K Tennant (Eds Handbook of research on sport psychology (pp 891-900) New York Macmillan

G111. D L . \& Deeter. T E (1988) Development of the Sport Orientation Questionnaire Re sear, $t$.

Quarterly for Exercise and Sport. 59. 191-202

Gould. D . \& Pick. S (1995) Sport psychology The Griffith era. 1920--1940 The Sport Psychology - 9,391-405 Heli. J . \& Henschen. K (1996) .Assessment in sport and exercise psychology In J L Van Raalte d. B W Brewer (Eds t. Exploring sport and exercise phsychology (pp 229-255) Washington. DC American Psychological Association

Landers. D M (1983) Whatever happened to theory testing in spor1 psychology' Journal of .Soir Psychology. 5. I 35-151

Lazarus. R S (1993) From psychological stress to the emotion. A history of changing outlooks

Review of Psychology. 44. 1-21

Lewin. K (1935) 4 dynamic theory of personality New York McGraw-Hill

Lewin. K I 1951) Field theory in social science New York Harper

Markus. H . \& Wurf. E (1987) The dynamic self-concep1 A social psychological perspective

Review of Psychology. 38. 299-337

Marsh. H W (1994) Sport motivation orientations Beware of tingle-tangle fallacies Journal of Sport \& Exercise Psychology-16. 365-380

Martens. R (1975) Sport Competition Anxiety Test Champaign. IL Human Kinetics

Martens. R (1987) Science. knowledge. and sport psychology The Sport Psychologist. 1 29-55 Martens. R .

Vealey. R S . \& Burton. D (1990) Competitive anxiety in sport Champaign. IL Human

Kinetics

Ostrow. A C (Ed ) (1990) Directors of psychological tests $w$ the snort and exercice science' Morgantown. WV Fitness Information Technology

Platt. J R (1964) Strong inference Science. 146 (3642), 347-352. 
Rejeski. W J (1996. May) Qualm of life in the elderly Application to physical activity Tutorial lecture given at the meeting of the American College of Sports Medicine. Cincinnati. OH

Rejeski. W J Brawley. L R . \& Shumaker. S A (1996) Physical activity and health-related quality of life In J O Holloszy (Ed ). Exercise and sport sciences reviews (Vol 24. pp 71-108) Baltimore Williams \& Wilkins

Roberts, G C (1993) Motivation in sport Understanding and enhancing the motivation and achievement of children. In R N Singer. M Murphey. \& L K Tennant (Eds ), Handbook of research on sport psychology (pp 405-420). New York Macmillan

Scanlan, T K . Stein, G L , \& Ravizza. K (1989) An in-depth study of former elite figure skaters Part 2 Sources of enjoymen1 Journal of Sport \& Exercise Psychology. 11, 65-83

Schutz. R W (1993). Methodological issues and measurement problems in sport psychology In S

Serpa. J Alves, V Ferreira. \& A Paulo-Brito (Eds.), Proceedings of the 8th World Congress of Sport Psychology (pp 119-131) Lisbon. Portugal International Society of Sport Psychology

Schutz, R W . \& Gessaroli, M E (1993) Use. misuse. and disuse of psychometrics in sport psychology research In R N Singer. M. Murphey, \& L K Tennant (Eds ). Handbook of research on sport psychology (pp 901-917) New York Macmillan

Smith, R E , Smoll. F L . \& Schutz, R W (1990) Measurement and correlates of sport-specific cognitive and somatic trai1 anxiety The Sport Anxiety Scale. Anxiety Research. 2, 263-280 Tutko. T A . Lyon. L P • \& Ogilvie. B C (1969) Athletic Motivation Inventory. San Jose. CA Institute for the Study of Athletic Motivation 